
базисной противоревматической терапии

\author{
Ирина Геннадьевна Кириллова*, Диана Сергеевна Новикова, \\ Татьяна Валентиновна Попкова, Елена Васильевна Удачкина, \\ Евгения Иннокентьевна Маркелова, Юлия Николаевна Горбунова, \\ Юлия Олеговна Корсакова, Светлана Николаевна Глухова
}

Научно-исследовательский институт ревматологии имени В.А. Насоновой Россия, 115522, Москва, Каширское шоссе, 34а

\begin{abstract}
Цель. Изучить клинические проявления и факторы, ассоциирующиеся с наличием хронической сердечной недостаточности (ХСН) у больных ранним ревматоидным артритом (РА) до назначения базисной противовоспалительной терапии.

Материал и методы. В исследование включено 74 пациента с верифицированным диагнозом PA (критерии ACR/EULAR, 2010 г.) 56 женщин (74\%), медиана возраста - 54 [46;61] года, длительность заболевания - 7 [4;8] мес; серопозитивные по IgM ревматоидному фактору (87\%) и/или антителам к циклическому цитруллинированному пептиду (100\%) до начала базисной терапии и терапии кортикостероидами. ХСН верифицировали в соответствии с актуальными рекомендациями. Оценка традиционных факторов риска сердечно-сосудистых заболеваний, атеросклероза сонных артерий по данным дуплексного сканирования и эхокардиография проведены до начала терапии у всех пациентов с ранним PA. Концентрацию NT-рroBNP определяли методом электрохемилюминесценции. Нормальный диапазон для NT-proBNP составляет <125 пг/мл.

Результаты. ХСН диагностирована у 24 (33\%) больных: у 23 пациентов - ХСН с сохраненной фракцией выброса и у 1 пациента - ХСН со сниженной. У $50 \%$ пациентов С РА в возрасте до 60 лет диагностирована ХСН. У 5 (21\%) больных отмечался І функциональный класс (ФК) по NYHA, у 15 (63\%) - II ФК, у 1(4\%) - III ФК. Положительная предсказательная ценность клинических симптомов не превышала 38\%. Все пациенты с ранним РА были разделены на 2 группы в зависимости от наличия ХСН. Пациенты с РА и ХСН были старше, имели более высокие значения индекса массы тела, у них чаще встречались артериальная гипертония, атеросклероз сонных артерий, ишемическая болезнь сердца (ИБС), также был статистически значимо выше уровень С-реактивного белка (СРБ), толщина интима-медиа (ТИМ) сонных артерий. С помощью пошагового линейного регрессионного анализа выявлены факторы, независимо ассоциирующиеся с развитием ХСН: абдоминальное ожирение, СРБ, уровень систолического артериального давления, дислипидемия, ТИМ сонных артерий, ИБС. Множественный коэффициент детерминации составил $\mathrm{R}^{2}=57,1$ (R-0,76, p<0,001). Уровень NT-proBNP у больных PA с XCH $(192,0$ [154,9; 255,7] пг/мл) был выше, чем у больных РА без XСН ( $77[41,1 ; 191,2]$ пг/мл) и в контроле $(49,0[33,2 ; 65,8]$ пг/мл), p<0,0001 и p=0,01, соответственно. Для исключения XCH у больных ранним PA наиболее оптимальный уровень NT-proBNP составил 150,4 пг/мл (чувствительность - 80\%, специфичность - 79\%), площадь под ROC-кривой = 0,957 (95\% доверительный интервал 0,913-1,002, p<0,001).

Заключение. У трети больных РА уже на ранней стадии заболевания выявляется XСН, преимущественно с сохраненной фракцией выброса. Факторами, ассоциирующимися с наличием ХСН, являются абдоминальное ожирение, СРБ, уровень систолического артериального давления, дислипидемия, ТИМ сонных артерий, ИБС.
\end{abstract}

Ключевые слова: ревматоидный артрит, хроническая сердечная недостаточность, NT-proBNP.

Для цитирования: Кириллова И.Г., Новикова Д.С., Попкова Т.В., Удачкина Е.В., Маркелова Е.И., Горбунова Ю.Н., Корсакова Ю.О., Глухова С.Н. Хроническая сердечная недостаточность у больных ранним ревматоидным артритом до назначения базисной противоревматической терапии. Рациональная Фармакотерапия в Кардиологии 2020;16(1):51-58. DOI:10.20996/1819-6446-2020-01-02

\title{
Chronic Heart Failure in Early Rheumatoid Arthritis Patients Prior to Basic Antirheumatic Therapy
}

Irina G. Kirillova*, Diana S. Novikova, Tatiana V. Popkova, Helen V. Udachkina, Evgenia I. Markelova, Yulia N. Gorbunova,

Yulia O. Korsakova, Svetlana N. Gluchova

Research Institute of Rheumatology named after V.A. Nasonova

Kashirskoe shosse 34a, Moscow, 115522 Russia

Aim. To study the clinical manifestations and factors associated with the presence of chronic heart failure (CHF) in patients with early rheumatoid arthritis (RA) prior to anti-inflammatory therapy. Material and methods. The study included 74 patients with valid diagnosis of RA (criteria ACR/EULAR, 2010), 56 women (74\%), median age - $54[46 ; 61]$ years, disease duration - $7[4 ; 8]$ months; seropositive for IgM rheumatoid factor (87\%) and/or antibodies to cyclic citrullinated peptide (100\%) prior to taking disease modifying anti-rheumatic drugs and glucocorticoids. CHF was verified in accordance with actual guidelines. The assessment of traditional risk factors for cardiovascular diseases, echocardiography, tissue Doppler imaging, carotid artery ultrasound, were carried out before the start of therapy in all patients with early RA. The concentration of NT-proBNP was determined by electrochemiluminescence. The normal range for NT-proBNP was less than $125 \mathrm{pg} / \mathrm{ml}$.

Results. CHF was diagnosed in 24 (33\%) patients: in 23 patients - CHF with preserved ejection fraction, in 1 patient - CHF with reduced ejection fraction. $50 \%$ of patients with RA under the age of 60 were diagnosed with CHF. NYHA class I was found in 5 (21\%) patients, class II - in 15 (63\%), class III - in 1 (4\%). Positive predictive value of clinical symptoms did not exceed 38\%. All patients with early RA were divided into two groups: 1 - with CHF, 2 - without CHF. Patients with RA+CHF compared with patients without CHF were older, had higher body mass index, frequency of carotid atherosclerosis, of ischemic heart disease (IHD), hypertension, C-reactive protein (CRP) levels and intima media thickness. Independent factors associated with the presence of CHF were identified by linear regression analysis: abdominal obesity, CRP level, systolic blood pressure, dyslipidemia, carotid intima thickness, IHD. The multiple coefficient of determination was $R^{2}=57.1(R-0.76, p<0.001)$. Level of NT-proBNP in RA patients with CHF (192.0 [154.9; 255.7] pg/ml) was higher than in RA patients without CHF (77 [41.1; 191.2] pg/ml) and in control (49.0 [33.2; 65.8] pg/ml), $p<0.0001$ and $p=0.01$, respectively. To exclude CHF in patients with early RA, the optimal NT-proBNP level was $150.4 \mathrm{pg} / \mathrm{ml}$ (sensitivity $-80 \%$, specificity $-79 \%$ ), the area under the ROC curve $=0.957$ (95\% confidence interval 0.913-1.002, $p<0.001$ ) 
Conclusion. CHF was detected in a third of RA patients at the early stage of the disease. Factors associated with the presence of $\mathrm{CHF}$ were abdominal obesity, CRP level, systolic blood pressure, dyslipidemia, intima media thickness, IHD.

Keywords: rheumatoid arthritis, chronic heart failure, NT-proBNP.

\section{The full English version of the article is available on the journal website: www.rpcardio.com}

For citation: Kirillova I.G., Novikova D.S., Popkova T.V., Udachkina H.V., Markelova E.I., Gorbunova Y.N., Korsakova Y.O., Gluchova S.N. Chronic Heart Failure in Early Rheumatoid Arthritis Patients Prior to Basic Antirheumatic Therapy. Rational Pharmacotherapy in Cardiology 2020;16(1):51-58. DOI:10.20996/1819-6446-2020-01-02

*Corresponding Author (Автор, ответственный за переписку): r.i.kirillova@yadndex.ru

Received/Поступила: 01.07.2019

Accepted/Принята в печать: 25.07.2019

В последние годы появляется все больше данных о высокой распространенности сердечной недостаточности (XCH) среди пациентов с ревматоидным артритом (РА) и увеличении смертности от декомпенсации ХСН в этой когорте больных [1-5]. Распространенность ХCH среди лиц старше 65 лет в общей популяции почти 10 больных на 1000 человек, и в 20\% случаев ХCH является причиной всех госпитализаций [6]. У больных PA XCH встречается в 2 раза чаще, чем у пациентов без РА [7].

В многочисленных исследованиях были выявлены структурные и функциональные изменения миокарда у больных РА без известных сердечно-сосудистых заболеваний, приводящих к нарушению диастолической функции миокарда [4,7-10]. По данным мета-анализа (25 исследований, 1614 больных РА, и 4222 - контроль) частота диастолической дисфункции левого желудочка (ДДЛЖ), индекс массы миокарда левого желудочка (ЛЖ), среднее артериальное давление (АД) в легочной артерии при РА выше, чем в контрольной группе. Фракция выброса (ФВ) в группах статистичеСКи значимо не различалась [11]. По данным J. Davis и соавт. у больных РА было выявлено преобладание XСH с сохраненной фракцией выброса (ХСНсФВ) по сравнению с контролем, но их смертность была выше, чем у пациентов с XСН без PA [12]. На сегодняшний день ни в одном исследовании не оценивалась функция миокарда в дебюте РА. Это важный вопрос, так как своевременное выявление и лечение XCH у больных РА может привести к снижению смертности.

Также мало что известно об особенностях клинической картины XСН у пациентов с РА по сравнению с населением в целом. Например, пациенты с РА могут предъявлять меньше жалоб на одышку при физической нагрузке из-за слабости, вызванной суставным синдромом, а отеки в области стоп могут связывать с артритом, а не с декомпенсацией сердечной деятельности [4]. Все это может приводить к поздней диагностике XСН у больных РА.
Следовательно, раннее выявление XСH у больных ранним РА для проведения активной профилактики и лечения этого осложнения имеет несомненный научный и практический интерес.

Цель исследования: изучить клинические проявления и факторы, ассоциирующиеся с наличием XСH у больных ранним РА до назначения базисной противовоспалительной терапии.

\section{Материал и методы}

В рамках исследования РЕМАРКА в исследование Включено 74 пациента с ранним РА. Критериями включения являлись: достоверный диагноз РА, длительность заболевания менее 1 года, позитивность по ревматоидному фактору (РФ) и/или антителам к циклическому цитруллинированному пептиду (АЦЦП), умеренная и высокая воспалительная активность заболевания до терапии базисными противовоспалительными препаратами и кортикостероидами. Характеристика пациентов с ранним РА представлена в табл. 1. Большинство больных составляли женщины. Пациенты имели умеренную и высокую активность воспалительного процесса (табл. 1).

На момент включения в исследование нестероидные противовоспалительные препараты (НПВП) принимала большая часть больных ранним РА. Кардиопротективные препараты регулярно принимали 34 (46\%) больных (табл. 2).

Все пациенты осмотрены кардиологом, выполнены Холтеровское мониторирование электрокардиограммы (ЭКГ) и суточное мониторирование АД, эхокардиография (ЭХО-КГ), дуплексное сканирование сонных артерий. Согласно актуальным рекомендациям [13] проводилась оценка традиционных факторов риска сердечно-сосудистых заболеваний (ССЗ). Диагноз XСН верифицировали в соответствии с рекомендациями по лечению и диагностике XСН (2013 г.) [14] при наличии у пациента четырех ключевых критериев: характерных симптомов и/или признаков ХСH 
Table 1. General characteristics of patients with early rheumatoid arthritis $(n=74)$

Таблица 1. Общая характеристика больных ранним PA $(n=74)$

\begin{tabular}{|c|c|}
\hline Параметр & Значение \\
\hline Возраст, лет & $56[46 ; 61]$ \\
\hline Женщины, n (\%) & $54(73)$ \\
\hline Длительность заболевания, мес & $7[4 ; 8]$ \\
\hline Системные проявления PA, n (\%) & $10(14)$ \\
\hline $\begin{array}{l}\text { Активность по DAS } 28, n(\%) \\
\text { умеренная }(3,2-5,1) \\
\text { высокая }(>5,1) \\
\end{array}$ & $\begin{array}{l}32(43,2) \\
42(56,8)\end{array}$ \\
\hline $\operatorname{lgM} P \Phi, n(\%)$ & $64(87)$ \\
\hline АЦЦП, n (\%) & $74(100)$ \\
\hline $\mathrm{CO}, \mathrm{Mm} / 4$ & $30[16,7 ; 48,5]$ \\
\hline СРБ, Мг/л & $22,6[6,7 ; 46,3]$ \\
\hline $\begin{array}{l}\text { Терапия до включения, n (\%) } \\
\text { НПВП, n (\%) }\end{array}$ & $46(63)$ \\
\hline \multicolumn{2}{|c|}{$\begin{array}{l}\text { Данные представлены в виде Ме [25\%; } 75 \% \text { ], если не указано иное } \\
\text { РА - ревматоидный артрит, АЦцП - антитела к циклическому цитруллинированному } \\
\text { пептиду, РФ - ревматоидный фактор, СОЭ - скорость оседания эритроцитов, } \\
\text { СРБ - С-реактивный белок, НПВП - нестероидные противовоспалительные препараты }\end{array}$} \\
\hline
\end{tabular}

Table 2. Cardiovascular therapy prior to inclusion in the study

Таблица 2. Сердечно-сосудистая терапия до включения в исследование

\begin{tabular}{|lc|}
\hline Терапия до включения & $\mathrm{n}(\%)$ \\
\hline Нитраты & $3(4)$ \\
\hline Бета-адреноблокаторы & $18(24)$ \\
\hline Антагонисты кальция & $2(3)$ \\
\hline Ингибиторы АПФ & $16(22)$ \\
\hline Блокаторы рецепторов ангиотензина II & $4(6)$ \\
\hline Диуретики & $9(12)$ \\
\hline Блокаторы І--каналов & $2(3)$ \\
\hline Антиагреганты & $8(11)$ \\
\hline Статины & $4(6)$ \\
\hline Агонисты имидазолиновых рецепторов & $1(1)$ \\
\hline Антиаритмические препараты & $1(1)$ \\
\hline АПФ - ангиотензинпревращающий фермент \\
\hline
\end{tabular}

(одышка, утомляемость, ограничение физической активности, отеки лодыжек), объективных признаков дисфункции сердца по данным ЭХО-КГ с тканевой допплерографией и по уровню NT-proBNP> 125 пг/мл. Также проводили ЭКГ и рентгенографию легких, тест 6-минутной ходьбы не проводился по причине ограничения подвижности пациентов с РА. В контрольную группу включены здоровые лица ( $n=27)$, у которых отсутствовали объективные признаки ХCH и без ревматических заболеваний. Группы были сопоставимы по возрасту и полу.

ЭХО-КГ исследование выполнялось согласно рекомендациям Американского общества по эхокардиографии $[15,16]$. Диастолическая дисфункция диагно- стировалась в соответствии с рекомендациями по определению ДДЛж [17]. Нормальная диастолическая функция оценивалась по индексу левого предсердия не выше $34 \mathrm{~cm}^{3} / \mathrm{M}^{2}$, e' (средняя скорость раннего движения септальной и боковой части кольца митрального клапана) \$9,0 см/с. К диастолической дисфункции ЛЖ по типу нарушения релаксации отнесены больные, у которых отношение $E / A<1,0$, индекс левого предсердия $\geqslant 34 \mathrm{~cm}^{3} / \mathrm{M}^{2}, \mathrm{E} / \mathrm{e}^{\prime} \leqslant 9,0 \mathrm{~cm} / \mathrm{c}$. Псевдонормальный тип ДДЛЖ определялся при отношении $E / A=1,0-2,0$, индексе левого предсердия $\geqslant 34 \mathrm{CM}^{3} / \mathrm{M}^{2}, \mathrm{E} / \mathrm{e}^{\prime}=9-15$.

Концентрацию NT-proBNP определяли методом электрохемилюминесценции с использованием тестсистемы Elecsys proBNP II (Roche Diagnostics, Швейцария). Нормальный диапазон для NT-proBNP составляет <125 пг/мл (согласно инструкции фирмы-изготовителя).

Статистическая обработка данных проводилась с помощью пакета прикладных программ SPSS 18.0. Pезультаты представлены в виде медианы (Ме) и межквартильного диапазона (25\%;75\%). Для сравнения двух независимых групп применялся непараметрический критерий Манна-Уитни. Анализ взаимосвязи двух признаков проводился с использованием непараметрического корреляционного анализа Спирмена. Положительная предсказательная ценность (ППЦ) рассчитывалась по формуле: ППЦ=ИП (истинно положительный)/ИП+ЛП (ложноположительный). Для поиска факторов, ассоциирующихся с наличием $\mathrm{XCH}$, проведен многофакторный регрессионный пошаговый анализ. Оптимальные уровни NT-proBNP в отношении риска развития ХСH определяли построением ROC-кривой. Результаты считались статистически значимыми при величине $p<0,05$.

\section{Результаты}

ХСН диагностирована у 24 (33\%) больных: у 23 пациентов - ХСНсФВ, у 1 пациента - ХСН со сниженной ФВ. ХСН выявлялась преимущественно у пациентов в возрасте 60-69 лет, однако у 50\% пациентов с PA в возрасте до 60 лет диагностирована ХCH (рис. 1). У 5 (21\%) больных отмечался І функциональный класс (ФК) по NYHA, 15 (63\%) - ॥ ФК, у 1 (4\%) - ІІІ ФК. Одышка выявлена у 21 (87\%) человека (ППЦ - 33\% ), у 6 (25\%) - отеки лодыжек (ППЦ - 35\%), у 24 (100\%) - утомляемость (ППЦ - 38\%).

Все пациенты с ранним РА были разделены на 2 группы в зависимости от наличия ХСН (табл. 3). Пациенты с РА и ХСН были старше, имели более высокие значения индекса массы тела (ИМТ), у них чаще встречались артериальная гипертония (АГ), атеросклероз сонных артерий, ишемическая болезнь сердца (ИБС), также статистически значимо выше уровень 


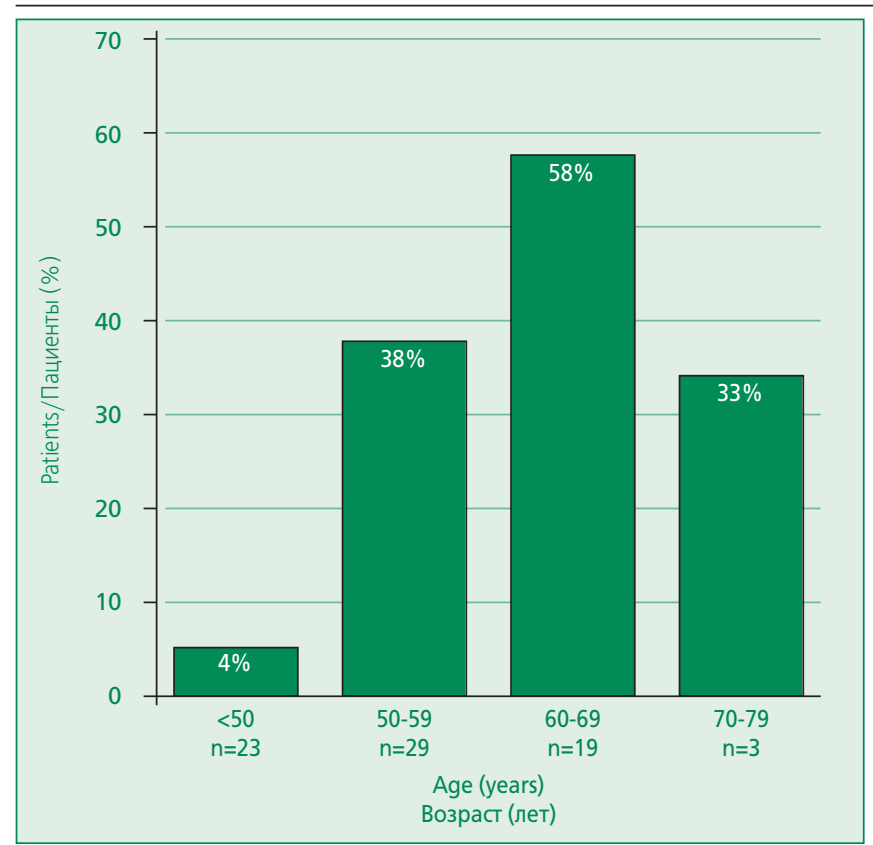

Figure 1. Chronic heart failure prevalence in patients with early rheumatoid arthritis depending on age

Рисунок 1. Частота ХСН у больных ранним РA в зависимости от возраста

С-реактивного белка (СРБ), больше толщина интимамедиа сонных артерий (ТИМ).

С целью поиска предикторов ХСН был проведен пошаговый линейный регрессионный анализ, где в качестве возможных предикторов тестировали пол, возраст, маркеры воспаления, индексы активности, традиционные факторы риска, СС3, сердечно-сосудистые препараты, нестероидные противовоспалительные препараты (НПВП). Множественный коэффициент детерминации $R^{2}=57,1$ ( $\left.R-0,76 ; p<0,001\right)$. Коэффициенты прогностической многофакторной модели диагностики ХСН представлены в табл. 4.

Была получена формула, с помощью которой можно оценить риск развития XСН у больных ранним PA:

XCH=0,249 ×абдоминальное ожирение (да/нет)+0,004× СРБ (мг/л)+0,255 ×дислипидемия (да/нет)+0,004× систолическое АД (мм рт.ст.)+0,758×толщина интимамедиа (мм)+0,227×ИБС (да/нет)-1,294.

Если значение, вычисленное по данной формуле, превышает величину 0,5, то можно считать риск наличия ХСН высоким. Построенная прогностическая модель имеет высокую точность предсказания: площадь под ROC-кривой 0,849, (95\% доверительный интервал [95\%ДИ] 0,76-0,94, p<0,001) с чувствительностью 88\% и специфичностью 88\%.

При проведении ЭХО-КГ в группе больных ранним РА с ХСН выявлено статистически значимое увеличение размера ЛП и индекс конечно-систолического объема предсердий (ИКСО ЛП), поскольку эти пока-
Table 3. Characteristics of patients with early rheumatoid arthritis depending on the presence of chronic heart failure

Таблица 3. Характеристика больных ранним РА в зависимости от наличия XCH

\begin{tabular}{|c|c|c|c|}
\hline Параметр & $\begin{array}{c}P A \subset X C H \\
(n=24)\end{array}$ & $\begin{array}{c}\text { РА без XCH } \\
(n=50)\end{array}$ & $p$ \\
\hline Возраст, лет & $61[58 ; 65]$ & $51[38 ; 57]$ & $<0,001$ \\
\hline Пол, м/ж, n (\%) & $5(21) / 19(79)$ & $15(30) / 35(70)$ & $>0,05$ \\
\hline САД, мм рт.ст. & $132[120 ; 140]$ & $120[100 ; 132]$ & $<0,01$ \\
\hline$A \Gamma, n(\%)$ & $10(83)$ & $26(52)$ & $<0,02$ \\
\hline Дислипидемия, n (\%) & $23(96)$ & $26(64)$ & $<0,01$ \\
\hline ОХС, ммоль/л & $5,6[5,1 ; 6,0]$ & $5,2[4,5 ; 6,03]$ & $>0,05$ \\
\hline ХС-ЛПНП, ммоль/л & $3,5[3,0 ; 4,3]$ & $3,4[2,8 ; 4,2]$ & $>0,05$ \\
\hline ХС-ЛПВП, ммоль/л & $1,4[0,96 ; 1,57]$ & $1,3[1,03 ; 1,6]$ & $>0,05$ \\
\hline Триглицериды, ммоль/л & $1,3[0,9 ; 1,8]$ & $0,9[0,8 ; 1,5]$ & $>0,05$ \\
\hline Гемоглобин, г/л & $136[114 ; 139,5]$ & $128[119,5 ; 136]$ & $>0,05$ \\
\hline ИМT, кг/M² & $28[25 ; 32]$ & $24[22 ; 29]$ & $<0,001$ \\
\hline $\mathrm{AO}, \mathrm{n}(\%)$ & $24(100)$ & $24(58)$ & $<0,001$ \\
\hline СД 2 типа, n (\%) & $2(8)$ & $3(6)$ & $>0,05$ \\
\hline$A C A, n(\%)$ & $21(91)$ & $23(49)$ & $<0,001$ \\
\hline TИM, MM & $0,95[0,89 ; 1,04]$ & $0,79[0,68 ; 0,93]$ & $<0,01$ \\
\hline$\overline{U Б C, n(\%)}$ & $9(38)$ & $3(6)$ & $<0,001$ \\
\hline DAS28 & $5,3[4,6 ; 6,4]$ & $5,3[5,0 ; 6,0]$ & $>0,05$ \\
\hline $\mathrm{CO}, \mathrm{Mm} / 4$ & $34[16 ; 56]$ & $27[16 ; 41]$ & $>0,05$ \\
\hline СРБ, Мг/л & $28[13 ; 91]$ & $20,0[5,6 ; 43]$ & $<0,04$ \\
\hline $\mathrm{H \sqcap BC}$ & $8(33)$ & $24(48)$ & $>0,05$ \\
\hline \multicolumn{4}{|c|}{ Данные представлены в виде Ме [25\%;75\%], если не указано иное } \\
\hline \multicolumn{4}{|c|}{ р - статистическая значимость различий (Манн-Уитни) } \\
\hline \multicolumn{4}{|c|}{$\begin{array}{l}\text { РА - ревматоидный артрит, ХСН - хроническая сердечная недостаточность, АГ - артериаль- } \\
\text { ная гипертония, АО - абдоминальное ожирение, АСА - атеросклероз сонных артерий, ИБС } \\
\text { - ишемическая болезнь сердца, ИМТ - индекс массы тела, НПВС - нестероидные противо- } \\
\text { воспалительные средства, ОХС - общий холестерин, САД - систолическое артериальное } \\
\text { давление, СД - сахарный диабет, СОЭ - скорость оседания эритроцитов, СРБ - С-реактив- } \\
\text { ный белок, ТИМ - толщина интима-медиа, ХС-лПНП - холестерин липопротеинов низкой } \\
\text { плотности, ХС-лПВП - холестерин липопротеинов высокой плотности }\end{array}$} \\
\hline
\end{tabular}

затели выступали в качестве критерия разделения на группы (табл. 5 ).

Ремоделирование миокарда ЛЖ отмечено как у больных с XCH (79\%), так и без XСH (30\%). У пациентов с РА и XСН чаще выявляется концентрическое ремоделирование миокарда ЛЖ (рис. 2).

Данные импульсно-волновой и тканевой допплерографии трансмитральных потоков статистически значимо различались в группах. У больных ранним РА с XCH отмечалось снижение показателя $\mathrm{E}$ и Е', отношения $E / A$, и увеличение показателя $A$, отношения $\mathrm{E} / \mathrm{E}^{\prime}$.

У всех больных PA с ХCH уровень NT-proBNP был выше $(192,0[154,9 ; 255,7]$ пг/мл), чем у пациентов без XCH $(77[41,1 ; 191,2]$ пг/мл) $(p<0,001)$ и в контроле $(49,0[33,2 ; 65,8]$ пг/мл, $p<0,0001)$. У пациентов с РА без XСН уровень NT-proBNP также был статистически значимо выше, чем в контроле $(p=0,01)$. 
Table 4. The regression coefficients for the prediction of chronic heart failure in patients with early rheumatoid arthritis

Таблица 4. Регрессионные коэффициенты прогноза ХCH у больных ранним РА

\begin{tabular}{lcccc} 
Модель & Коэффициент & $p$ & \multicolumn{2}{c}{$95 \% д И$} \\
\hline $\begin{array}{l}\text { Абдоминальное } \\
\text { ожирение, да/нет }\end{array}$ & 0,249 & 0,025 & 0,032 & 0,466 \\
\hline СРБ, мг/л & 0,004 & 0,003 & 0,001 & 0,006 \\
\hline Дислипидемия, да/нет & 0,255 & 0,024 & 0,034 & 0,476 \\
\hline САД, мм рт.ст. & 0,004 & 0,144 & 0,001 & 0,010 \\
\hline Толщина интима-медиа & & & & \\
максимальная, мм & 0,758 & 0,026 & 0,091 & 1,423 \\
\hline ИБС, да/нет & 0,226 & 0,073 & 0,021 & 0,474 \\
\hline САД сисолчесо & & с & С-реак
\end{tabular}

САД - систолическое артериальное давление, СРБ - С-реактивный белок, ИБС - ишемическая болезнь сердца, ДИ - доверительный интервал

Для определения оптимального уровня NT-proBNP у больных РА для исключения ХСН была построена ROC-кривая. Для исключения XCH наиболее оптимальный уровень NT-proBNP составил 150,4 пг/мл (чувствительность - 80\%, специфичность - 79\%), площадь под ROC-кривой=0,957 (95\%ДИ 0,913$1,002, p<0,001)$, ППЦ - 75\% (табл. 6).

\section{Обсуждение}

Наше исследование является первой работой, направленной на изучение частоты и факторов риска XCH у больных ранним РА до назначения базисных противовоспалительных препаратов и кортикостероидов. В нашей когорте больных ранним РА клинически выраженная XCH диагностирована у 33\% больных. Имеются данные о том, что у пациентов с РА уже в дебюте заболевания XCH диагностируется у 0,7\% больных, а через 15 лет встречается уже у 10\% больных [18]. В датском популяционном исследовании продемонстрировано увеличение риска развития ХСН в 2,38 раза от дебюта и в течение первого года заболевания [19]. По разным данным у больных РА распространенность ХСН колеблется от 2,4 до 11,6\% [19-22]. Такую существенную разницу можно объяснить тем, что во многих исследованиях учитывалась только клинически выраженная XCH, требующая лечения или госпитализации, не проводилось ЭХО-КГ с тканевой допплерографией и определение уровня NT-proBNP [22]. Кроме того, в нашей когорте у всех больных была умеренная или высокая активность заболевания, тогда как в представленных исследованиях были пациенты с низкой или умеренной активностью РА. Так, по нашим данным клинические симптомы ХСН продемонстрировали низкую ППЦ для верификации диагноза (одышка 33\%, отеки лодыжек - 35\%, утомляемость - 38\%). В исследовании Т. Schau и соавт. также выявили у больных РА низкую ППЦ одышки - 42\%, отеков - 39\%,
Table 5. Echocardiographic parameters in patients with early rheumatoid arthritis depending on the presence of chronic heart failure

Таблица 5. Эхокардиографические показатели у больных ранним РА в зависимости от наличия ХCH

\begin{tabular}{|c|c|c|c|}
\hline Параметр & $\begin{array}{c}\text { PACXCH } \\
(n=24)\end{array}$ & $\begin{array}{c}\text { PA без XCH } \\
(n=50)\end{array}$ & $p$ \\
\hline ЛП, мм & $38,2[35,5 ; 39,4]$ & $34,7[31,9 ; 38,2]$ & 0,01 \\
\hline ИКСО ЛП, $\mathrm{CM}^{3} / \mathrm{M}^{2}$ & $38,8[35,9 ; 41,9]$ & $21,2[19,4 ; 33,0]$ & $<0,0001$ \\
\hline КДО ЛЖ, см³ & $74,5[62,7 ; 87,0]$ & $79,9[69,3 ; 94,9]$ & $>0,05$ \\
\hline ТМЖП, МM & $10,4[9,7 ; 11,9]$ & $9,6[8,4 ; 11,3]$ & $<0,04$ \\
\hline ТЗСЛЖ, мм & $10,3[9,5 ; 10,9]$ & $9,6[8,2 ; 10,8]$ & $<0,02$ \\
\hline ФВ ЛЖ, \% & $63[59 ; 68]$ & $67[61 ; 70]$ & $>0,05$ \\
\hline EЛЖ, M/c & $0,7[0,6 ; 0,7]$ & $0,8[0,7 ; 0,9]$ & $<0,004$ \\
\hline АЛ $\Psi_{1} \mathrm{M} / \mathrm{C}$ & $0,8[0,7 ; 0,9]$ & $0,6[0,5 ; 0,7]$ & $<0,0001$ \\
\hline E/AЛЖ, м/с & $0,9[0,8 ; 0,9]$ & $1,4[1,1 ; 1,6]$ & $<0,05$ \\
\hline DT ЛЖ, MC & $220,5[191,8 ; 252,2]$ & $213,5[199,1 ; 246,0]$ & $>0,05$ \\
\hline IVRT ЛЖ, MC & $100,2[81,3 ; 118,3]$ & $90,4[79,4 ; 103,28]$ & $>0,05$ \\
\hline$E^{\prime}, M / C$ & $0,09[0,07 ; 1,0]$ & $0,13[0,12 ; 0,17]$ & $<0,0001$ \\
\hline $\mathrm{E} / \mathrm{E}^{\prime}$ & $8,2[6,0 ; 10,7]$ & $5,9[5,1 ; 7,6]$ & $<0,05$ \\
\hline$\pi \Gamma n(\%)$ & $3(13 \%)$ & $2(4 \%)$ & $>0,05$ \\
\hline
\end{tabular}

Данные представлены в виде медианы с межквартильным диапазоном, если не указано иначе р - статистическая значимость различий (Манн-Уитни)

PA - ревматоидный артрит, ХСН - хроническая сердечная недостаточность, ЛЖ - левый желудочек, E - пиковая скорость раннего диастолического наполнения, A - пиковая скорость позднего диастолического наполнения, Е/А - отношение максимальной скорости кровотока во время раннего диастолического наполнения (Е) к максимальной скорости потока во время предсердной систолы (А), ИКСО ЛП - индекс конечно-систолического объема левого предсердия, КГМЛЖ - концентрическая гипертрофия миокарда ЛЖ, КДО - конечно-диастолический объем, КРМЛЖ - концентрическое ремоделирование миокарда ЛЖ, ЛГ- легочная гипертензия, ЛП -левое предсердие, ТЗСЛЖ - толщина задней стенки левого желудочка, ТМЖП - толщина межжелудочковой перегородки, ФВ - фракция выброса ЛЖ, ЭГМЛЖ эксцентрическая гипертрофия миокарда ЛЖ, А' - скорость движения фиброзного кольца в позднюю диастолу, DT - время замедления раннего диастолического наполнения, E' - скорость движения фиброзного кольца в раннюю диастолу, Е/Е' - отношение максимальной скорости раннего диастолического наполнения митрального (трикуспидального) потока к ранней диастолической скорости движения фиброзного кольца митрального клапана (трикуспидального клапана), IVRT - время изоволюмической релаксации

Table 6. Sensitivity, specificity, positive predictive value of the NT-proBNP level

Таблица 6. Чувствительность, специфичность, положительная предсказательная ценность уровня NT-proBNP

\begin{tabular}{lccc}
\hline Уровень NT-proBNP & Чувствительность & Специфичность & ППЦ \\
\hline 125 пг/Мл & $100 \%$ & $75 \%$ & $41 \%$ \\
\hline 150 пг/Мл & $80 \%$ & $79 \%$ & $75 \%$ \\
\hline 220 пг/мЛ & $48 \%$ & $88 \%$ & $42 \%$ \\
\hline ППЦ - положительная предсказательная ценность & & \\
\hline
\end{tabular}

хрипов в легких - 38\%, тогда как у пациентов с XCH без РА отмечена более высокая ППЦ отеков - 67\% [4]. Низкая ППЦ клинических симптомов у больных РА объясняется тем, что данные проявления могут наблюдаться у больных РА без ХCH в рамках основного заболевания. Эти результаты подтверждают трудность диагностики XСН при РА и необходимость применения 


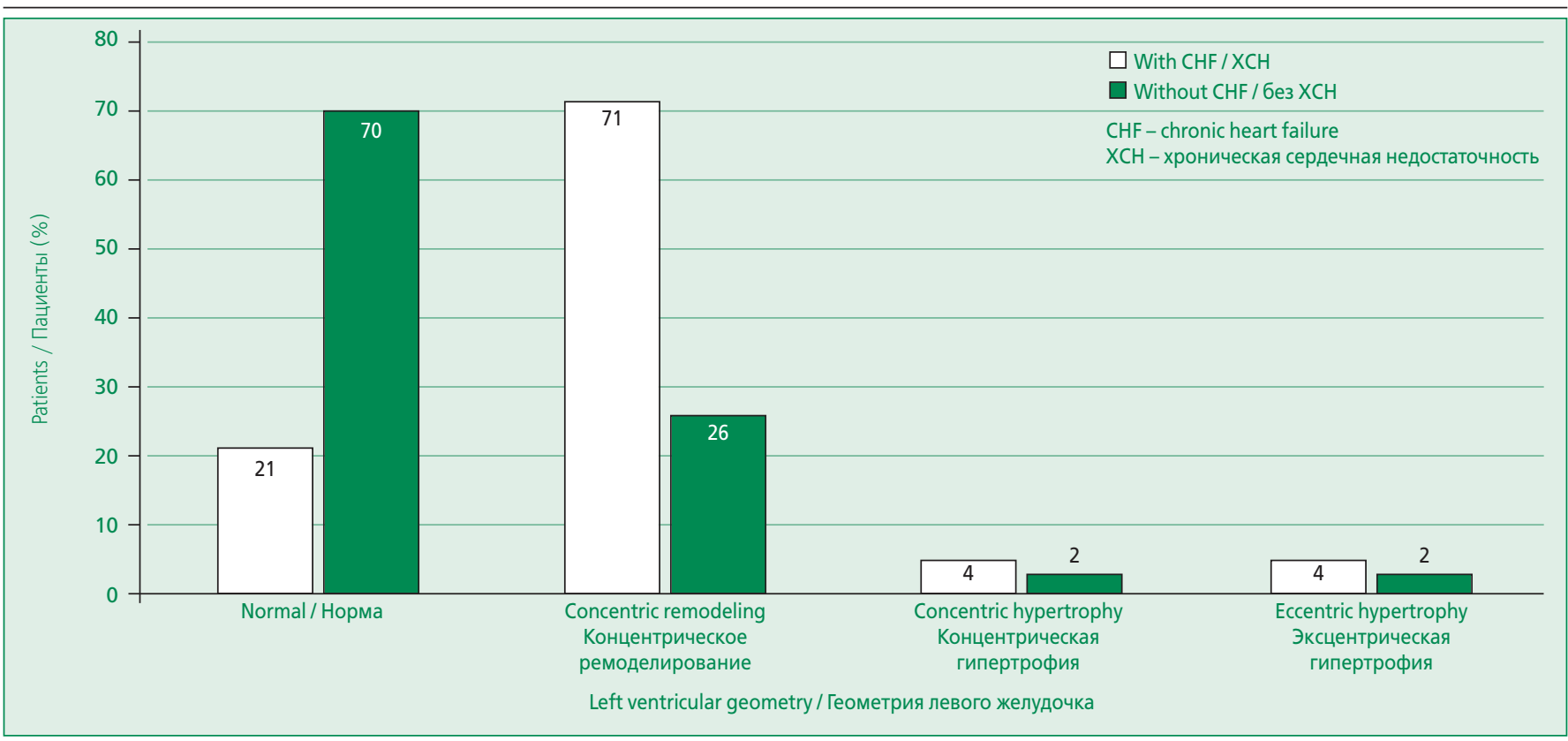

Figure 2. Types of changes in left ventricular geometry in patients with early rheumatoid arthritis depending on chronic heart failure

Рисунок 2. Виды изменения геометрии ЛЖ у больных ранним РА в зависимости от ХСН

инструментальных и лабораторных методов для верификации диагноза.

У больных ранним РА ХCH в основном представлена ХСНсФВ. Наши данные согласуются с результатами исследований, имеющихся в литературе. По данным Т. Schau и соавт. ХСНсФВ выявлена у 23\% больных РА, которые уже получали противоревматическую терапии [4], а K. Liang и соавт. показали, что у больных РА с ХСН ФВ была выше, чем у пациентов с XCH без PA (50\% против 47\%; p<0,007) и являлась преимущественно диастолическим вариантом [23].

В нашем исследовании выявлено, что у больных ранним РА моложе 60 лет ХСН встречается в 50\% случаев. Имеются данные о том, что ХСН у больных РА развивается на 10 лет раньше, чем в общей популяции [1].

При проведении многофакторного анализа мы впервые выявили факторы, ассоциирующиеся с ХCH у больных ранним РА. В прогностическую модель вошли наличие абдоминального ожирения, дислипидемии, уровень САД, ТИМ, ИБС, а также уровень СРБ. Ожирение может приводить к развитию ХСН с помощью различных механизмов (увеличение объема циркулирующей крови, увеличение сердечного выброса, гипертрофии левого желудочка, ДДЛж, ожирение сердца) $[24,25]$. По данным J. Davis и соавт. у больных РА с ХСН выше были показатели ИМТ (23\% и 10\% $(p=0,002)$, САД (отношение шансов [ОШ] 0,58; 95\%ДИ 0,38-0,89) и диастолического АД (ДАД) (ОШ 0,34; 95\%ДИ 0, 19-0,60) по сравнению с пациентами с XСН без PA [12]. Важно отметить, что наличие АГ было тесно связано с преобладанием ХСН в исследо- вании F. Wolf и др. (ОШ 2,6; 95\%ДИ 2, 1-3,2) [1]. Выявлена связь между АГ и повышенным риском развития ХCH у больных РА в течение в среднем 11,8 лет наблюдения [2], а также преобладание АГ у больных РА и XCH (84\%) по сравнению с пациентами без сердечной недостаточности (47\%) [4].

По данным шведского регистра в дебюте РА отмечается значимое увеличение риска XCH неишемической и ишемической этиологии (отношение рисков 1,22 и 1,27, соответственно) [26]. Недавно перенесенный ИМ (в течение 6-ти мес) и ИМ в анамнезе имеют статистически значимые корреляции с ХCH у больных РА (ОШ 16,1; 95\%ДИ 11,0-23,7 и ОШ 6,6; 95\%ДИ 5,4-8,0, соответственно) [1]. В исследовании P. Nicola и др. ИБС (в том числе, ИМ и стенокардия) и традиционные факторы риска ССЗ чаще приводили к развитию ХСН у РФ-отрицательных, но не РФ-позитивных пациентов с РА [2]. Субклинический атеросклероз сонных артерий чаще выявляется у больных РА, чем в контроле [27].

По данным C. Garza-García и соавт. у больных PA выявили, что наличие дислипидемии является одним из факторов риска развития ДДЛж [28]. Однако прямое влияние нарушения липидного обмена и субклинического атеросклероза на развитие XСН не ишемической этиологии не изучено. Также было продемонстрировано, что повышение уровня СРБ> 10 мг/л увеличивает риск развития $\mathrm{XCH}$ у больных РА (ОШ 2,6, 95\%дИ 0,8-8,0) [4].

Таким образом, на развитие ХCH у больных РА оказывают как традиционные факторы риска ССЗ, так и наличие воспаления. 
Мы впервые продемонстрировали изменение эхокардиографических показателей у пациентов с ранним PA. В нашем исследовании у больных ранним РА и ХСН ФВ Лж была выше 60\%, и статистически значимо не различалась у больных с ХCH и без ХСН. У одного пациента с постинфарктным кардиосклерозом и реваскуляризацией в анамнезе отмечено снижение ФВ до 39\%. В ряде исследований также были выявлены высокие показатели ФВ ЛЖ у больных РА с ХCH $[23,29]$. Можно предположить, что XСН у больных РА развивается в основном за счет нарушения диастолической функции миокарда.

Отмечена высокая частота изменения геометрии ЛЖ по данным ЭХО-КГ у больных ранним РА с ХСН. Наиболее частым вариантом изменения геометрии лж у больных как с ХCH, так и без ХСН являлось концентрическое ремоделирование миокарда Лж (71\% и 27\%, соответственно). По данным Г.Б. Колотовой нормальная геометрия ЛЖ была изменена в 65\% случаев у больных с серопозивным РА [29]. В исследовании Schau T. и соавт. также наблюдалось превышение частоты концентрического ремоделирования миокарда Лж у больных РА и ХСН по сравнению с пациентами без РА (48\% против 17\%; p=0,001) [4]. Предполагается, что изменение геометрии левого желудочка является ранним признаком повреждения миокарда, а также триггером для развития ХCH [30]. у больных с XCH в общей популяции чаще всего выявляется эксцентрическая гипертрофия ЛЖ по данным ЭХО-КГ, в отличие от больных ранним РА. Данную особенность можно объяснить тем, что у больных РА на геометрию ЛЖ преимущественно влияет воспаление, которое приводит к фиброзу миокарда, что способствует развитию ДДЛЖ и ХСН у больных РА. У пациентов с бессимптомной ХСН или наличием ИБС было показано, что при повышении уровня интерлейкина-б, СРБ, фактора некроза опухоли $\alpha$ риск развития ХСН в 2-4 раза выше, чем у пациентов с низкими уровнями этих маркеров и медиаторов воспаления [30]. Другие исследователи показали наличие отрицательной корреляционной связи между уровнем фактора некроза опухоли $\alpha$ и отношением E/A [31].

В общей популяции диагностически значимый уровень NT-proBNP для выявления стабильной ХCH составляет > 125 пг/мл с чувствительностью $88 \%$ и спе-

\section{References / Литература}

1. Wolfe F., Michaud K. Heart failure in rheumatoid arthritis: rates, predictors, and the effect of anti-tumor necrosis factor therapy. Am J Med. 2004;116:305-11. DOI:10.1016/j.amjmed.2003.09.039.

2. Nicola P.J., Crowson C.S., Maradit-Kremers H., et al. Contribution of congestive heart failure and ischemic heart disease to excess mortality in rheumatoid arthritis. Arthritis Rheum. 2006;54:60-7. DOI:10.1002/art.21560

3. Crowson C.S., Nicola P.J., Kremers H.M., et al. How much of the increased incidence of heart failure in rheumatoid arthritis is attributable to traditional cardiovascular risk factors and ischemic heart disease? Arthritis Rheum. 2005;52:3039-44. DOI:10.1002/art.21349. цифичностью 92\% [32]. В нашей когорте больных ранним РА уровень NT-proBNP, равный 125 пг/мл, продемонстрировал низкую ППЦ - 41\%. Для больных ранним РА оптимальной чувствительностью, специфичностью и ППЦ обладает более высокий уровень NT-proBNP, равный 150,4 пг/мл (с чувствительностью 80\% и специфичностью 79\%). Также L. Tomás и соавт. показали низкую чувствительность/специфичность (69\%/51\%), положительную (34\%) и отрицательную предсказательную ценность (19\%) уровня NT-proBNP> 125 пг/мл для выявления любой патологии сердца [31]. Вопрос, чем обусловлены более высокие значения уровня NT-proBNP для XCH у больных PA, требует дальнейшего изучения, так как на повышение уровня NT-proBNP у больных PA оказывают влияние как поражение сердечной мышцы на фоне XСН, так и воспаление при РА.

Ограничения исследования. Для нашего исследования имеется ограничение, связанное с небольшим количеством больных с ранним РА и ХСН. Так, для статистически значимой оценки частоты ХCH в разных возрастных группах необходимо большее количество пациентов с ранним РА.

\section{Заключение}

Настоящее исследование показывает, что у трети больных РА уже на ранней стадии заболевания выявляется $\mathrm{XCH}$, преимущественно с сохраненной ФВ. Факторами, ассоциирующимися с наличием XCH, являются абдоминальное ожирение, уровень СРБ, САД, дислипидемия, ТИМ, ИБС. У пациентов с ранним РА диагностически значимый уровень NT-proBNP для исключения ХCH выше (150,4 пг/мл), чем у пациентов без РА (125 пг/мл). Для пациентов с РА с высокой и умеренной активностью основное внимание должно быть направлено на скрининг факторов риска ССЗ и контроль воспаления для профилактики развития и прогрессирования ХСН.

Конфликт интересов. Все авторы заявляют об отсутствии потенциального конфликта интересов, требующего раскрытия в данной статье.

Disclosures. All authors have not disclosed potential conflicts of interest regarding the content of this paper.

\footnotetext{
4. Schau T., Gottwald M., Arbach O., et al. Increased prevalence of diastolic heart failure in patients with rheumatoid arthritis correlates with active disease, but not with treatment type. J Rheumatol. 2015;42(11):2029-37. DOI:10.3899/jrheum.141647

5. Novikova D.S., Kirillova I.G., Udachkina E.V., Popkova T.V. Chronic heart failure in patients with rheumatoid arthritis (part 1): prevalence, peculiarities of etiology and pathogenesis. Rational Pharmacotherapy in Cardiology. 2018;14(5):703-10 (In Russ.) [Новикова Д.С., Кириллова И.Г., Удачкина Е.В., Попкова Т.В. Хроническая сердечная недостаточность у больных ревматоидным артритом (часть 1) распространенность, особенности этиологии и патогенеза. Рациональная Фармакотерапия в Кардиологии. 2018;14(5):703-710]. DOI:10.20996/1819-6446-2018-14-5-703-710.
} 
6. Belenkov Yu. N. Patients with CHF in the Russian outpatient practice: features of the contingent, diagnosis and treatment (based on EPOHA-0-CHF study). Heart Failure. 2004;5(1):4-7 (In Russ.) [Eeленков, Ю.Н. Больные с ХСН в российской амбулаторной практике: особенности контингента, диагностики и лечения (по материалам исследования ЭПОХА-О-ХСН). Сердечная НедостаточHость. 2004;5(1):4-7]

7. Mustonen J., Laakso M., Hirvonen T., et al. Abnormalities in left-ventricular diastolic function in malepatients with rheumatoid-arthritis without clinically evident cardiovascular-disease. Eur J Clin Invest. 1993:23:246-53. DOI:10.1111/j.1365-2362.1993.tb00769.x.

8. Corrao S., Salli L., Arnone S., et al. Echo- Doppler left ventricular filling abnormalities in patients with rheumatoid arthritis without clinically evident cardiovascular disease. Eur J Clin Invest. 1996;26:2937. DOI:10.1046/j.1365-2362.1996.133284.x.

9. Wislowska M., Sypula S., Kowalik I. Echocardiographic findings, 24-hour electrocardiographic Holter monitoring in patients with rheumatoid arthritis according to Steinbrocker's criteria, functional index, value of Waaler-Rose titre and duration of disease. Clin Rheumatol. 1998;17:369-77. DOI:10.1007/bf01450894.

10. Birdane A., Korkmaz C., Ata N., et al. Tissue Doppler imaging in the evaluation of the left and right ventricular diastolic functions in rheumatoid arthritis. Echocardiography. 2007;24:485-93.

11. Aslam F., Bandeali S.J., Khan N.A., Alam M. Diastolic dysfunction in rheumatoid arthritis: a metaanalysis and systematic review. Arthritis Care Res (Hoboken). 2013;65(4):534-43. DOI:10.1002/acr.21861

12. Davis III J.M., Roger V.L., Crowson C.S., et al. The presentation and outcome of heart failure in persons with rheumatoid arthritis differs from that of the general population. Arthritis Rheum. 2008;58(9):2603-2611. DOI:10.1002/art.23798

13. Recommendations for cardiovascular prevention. The Committee of Russian Society of Cardiology (RSC) experts. Kardiovaskuljarnaja terapija i profilaktika 2011;10(6) 1-44 (In Russ.) [Рекомендации по кардиоваскулярной профилактике. Комитет экспертов РКО. Кардиоваскулярная Терапия и Профилактика. 2011;10(6):1-44]. DOI:10.15829/1728-8800-2011-6.

14. National recommendations of Society of Heart Failure Specialists (SHFS), Russian Society of Cardiology (RSC) and Russian Scientific Medical Society of Internal Medicine (RSMSIM) on the diagnosis and treatment of chronic heart failure (fourth revision). Heart Failure. 2013;81(7):379-472 (In Russ.) [Национальные рекомендации ОССН, РКО и РНMOT по диагностике и лечению хронической сердечной недостаточности (четвертый пересмотр). Сердечная Недостаточность. 2013;81(7):379-472]. DOI:10.18087/rhfj.2013.7.1860

15. Lafitte $S$. Do we need new echocardiographic prognosticators for the management of heart failure patients? J. Am Coll Cardiol. 2009;54:625-7. DOI:10.1016/j.jacc.2009.04.058.

16. Lang R.M., Bierig M., Devereux R.B., et al. Recommendations for chamber quantification. Eur. J Echocardiogr. 2006;7:79-108. DOI:10.1016/j.euje.2005.12.014

17. Nagueh S., Appleton C., Gillebert T., et al. Recommendations for the evaluation of left ventricular diastolic function by echocardiography. Eur J Echocardiogr. 2009;10(2):165-93. DOI:10.1093/ejechocard/jep007.

18. Norton S., Koduri G., Nikiphorou E. Study of baseline prevalence and cumulative incidence of comorbidity and extra-articular manifestations in RA and their impact on outcome. Rheumatology. 2013;52:99-110. DOl:10.1093/rheumatology/kes262.

\section{About the Authors: \\ Irina G. Kirillova - MD, Researcher, Systemic Rheumatic Diseases Laboratory, Research Institute of Rheumatology named after} V.A. Nasonova

Diana S. Novikova - MD, PhD, Leading Researcher, Systemic Rheumatic Diseases Laboratory, Research Institute of Rheumatology named after V.A. Nasonova

Tatiana V. Popkova - MD, PhD, Leading Researcher, Systemic Rheumatic Diseases Laboratory, Research Institute of Rheumatology named after $V$.A. Nasonova

Helen V. Udachkina - MD, Researcher, Rheumocardiology Laboratory, Research Institute of Rheumatology named after V.A. Nasonova Evgenia I. Markelova - MD, Senior Researcher, Systemic Rheumatic Diseases Laboratory, Research Institute of Rheumatology named after V.A. Nasonova

Yulia N. Gorbunova - MD, Researcher, Systemic Systemic Rheumatic Diseases Laboratory, Research Institute of Rheumatology named after V.A. Nasonova

Yulia O. Korsakova - MD, Doctor of Ultrasonic Diagnostics, Laboratory of Instrumental and UItrasonic Diagnostics, Research Institute of Rheumatology named after V.A. Nasonova

Svetlana N. Gluchova - Researcher, Educational and Methodical Department, Research Institute of Rheumatology named after V.A. Nasonova
19. Løgstrup B.B., Ellingsen, T., Pedersen A.B., Kjaersgaard A. et al. Development of heart failure in patients with rheumatoid arthritis: A Danish population-based study. Eur I Clin Invest. 2018:48(5):e12915. DOI:10.1111/eci.12915.

20. Nicola P.J., Maradit-Kremers H., Roger V.L., et al. The risk of congestive heart failure in rheumatoid arthritis: A population-based study over 46 years. Arthritis Rheum. 2005:52:412-20. DOI:10.1002/art.20855

21. Khalid U., Egeberg A., Ahlehoff 0 ., et al. Incident heart failure in patients with rheumatoid arthritis: a nationwide cohort study. J Am Heart Assoc. 2018;7(2).e007227. DOI:10.1161/JAHA 117.007227.

22. Hunt S.A., Baker D.W., Chin M.H., et al. ACC/AHA guidelines for the evaluation and management of chronic heart failure in the adult: executive summary. J Am Coll Cardiol. 2013;62 (16):1495-539 DOI:10.1016/j.jacc.2013.05.020.

23. Liang K.P., Myasoedova E., Crowson C.S., et al. Increased prevalence of diastolic dysfunction in rheumatoid arthritis. Ann Rheum Dis. 2010;69(9):1665-70. DOI:10.1136/ard.2009.124362.

24. Kenchaiah S., Evans J.C., Levy D., et al. Obesity and the risk of heart failure. N Engl J Med. 2002;347:305-13. DOI:10.1056/NEJMoa020245

25. Slack J.D., Waller B. Acute congestive-heart-failure due to the artritis of rheumatoid-arthritis: Early diagnosis by endomyocardial biopsy - a case-report. Angiology. 1986;37:477-82. DOI:10.1177/000331978603700609.

26. Mantel A., Holmqvist M., Andersson D.C. Association between rheumatoid arthritis and risk of ischemic and nonischemic heart failure. J Am Coll Cardiol. 2017;69(10):1275-85. DOI:10.1016/j.jacc.2016.12.033.

27. Gottdiener J. S., Arnold A. M., Aurigemma G. P., et al. Predictors of congestive heart failure in the elderly: the cardiovascular health study. J Am Coll Cardiol. 2000;35:1628-37. DOI:10.1016/s07351097(00)00582-9.

28. Garza-García C., Sánchez-Santillán R., Orea-Tejeda A., et al. Risk factors for asymptomatic ventricular dysfunction in rheumatoid arthritis patients. ISRN Cardiol. 2013;635439. DOI:10.1155/2013/635439.

29. Kolotova G.B. Morphofunctional state peculiarities and types of left heart remodeling in patients with seropositive and seronegative rheumatoid arthritis. Ul'trazvukovaja i Funkcional'naja Diagnostika. 2008;3:35-41 (In Russ.) [Колотова Г. Б. Особенности морфофункционального состояния и типь ремоделирования левых отделов сердца у пациентов с серопозитивным и серонегативным ревматоидным артритом. Ультразвуковая и Функциональная Диагностика. 2008;3:35-41].

30. Maradit-Kremers H., Nicola P.J., Crowson C.S., et al. Raised erythrocyte sedimentation rate signals heart failure in patients with rheumatoid arthritis. Ann Rheum Dis. 2007;66:76-80. DOI:10.1136/ard.2006.053710.

31. Tomáś L., Lazúrová I., Pundová L., et al. Acute and long-term effect of infliximab on humoral and echocardiographic parameters in patients with chronic inflammatory diseases. Clin Rheumatol. 2013;32:61-6. DOI:10.1007/s10067-012-2091-4.

32. Hess G, Runkel S, Zdunek D. N-terminal pro-brain natriuretic peptide (NT-proBNP) in healthy blood donors and in patients from general practitioners with and without a diagnosis of cardiac disease. Clin Lab. 2005;51(3-4):167-72.

\section{Сведения об авторах: \\ Кириллова Ирина Геннадьевна - Н.С., лаборатория \\ системных ревматических заболеваний, НИИР}

им. В.А. Насоновой

Новикова Диана Сергеевна - Д.м.н., В.Н.С., лаборатория

системных ревматических заболеваний, НИИР

им. В.А. Насоновой

Попкова Татьяна Валентиновна - Д.М.Н., В.Н.С., лаборатория

системных ревматических заболеваний, НИИР

им. В.А. Насоновой

Удачкина Елена Васильевна - Н.С., лаборатория

ревмокардиологии, НИИР им. В.А. Насоновой

Маркелова Евгения Иннокентьевна - С.н.С., лаборатория

системных ревматических заболеваний, НИИР

им. В.А. Насоновой

Горбунова Юлия Николаевна - Н.С., лаборатория системных ревматических заболеваний, НИИР им. В.А. Насоновой

Корсакова Юлия Олеговна - врач, лаборатория

инструментальной и ультразвуковой диагностики, НИИР

им. В.А. Насоновой

Глухова Светлана Николаевна - Н.С., учебно-методический отдел, НИИР им. В.А. Насоновой 